\title{
Study on Online Teaching of High Frequency Circuit under COVID-19 Epidemic
}

\author{
Haijiang Hu, Shaojing Song*, Yu Chai, Yumei Gong \\ College of Engineering, Shanghai Polytechnic University, Shanghai, China \\ Email: *sjsong@sspu.edu.cn
}

How to cite this paper: $\mathrm{Hu}, \mathrm{H}$. J., Song, S. J., Chai, Y., \& Gong, Y. M. (2020). Study on Online Teaching of High Frequency Circuit under COVID-19 Epidemic. Open Journal of Social Sciences, 8, 493-496.

https://doi.org/10.4236/jss.2020.83041

Received: March 11, 2020

Accepted: March 28, 2020

Published: March 31, 2020

\begin{abstract}
Most schools close their campus for the safety of students and teachers under COVID-19 epidemic. Online teaching is used in most schools and universities widely in spring term 2020. This paper studies on the online teaching method and results in online teaching of high frequency circuit, which is useful for online teaching of electronic engineering. In the online class, we use the discussion as the main method instead of the lecture. Students study the course contents before class. Most students are satisfied with the online teaching method. This online teaching method should be applied in other courses teaching in online university education.
\end{abstract}

\section{Keywords}

Online Teaching, High Frequency Circuit, Electronic Engineering, Simulation, COVID-19

\section{Introduction}

Since COVID-19 spreads around the world very rapidly, the global economics and the people life suffer severe influence. In education, most schools close their campus for the safety of students and teachers. In order to keep the normal teaching activities, online teaching (Goodyear et al., 2001; Nelson, 2010) is used in most schools and universities widely in spring term 2020. Although online reaching grows up rapidly with the development of Internet, the classroom teaching is the major style of education yet (Cuellar, 2002). Because of COVID-19, most schools and universities have to use the online teaching instead of the classroom teaching. In this paper, we study on the teaching method and results in online teaching of high frequency circuit, which is useful for online teaching of electronic engineering. 
The high frequency circuit is a main course of electronic engineering which includes high frequency signal amplification, high frequency power amplification, oscillator, modulation and demodulation, RF sender and receiver, and analog filter. The students are required to understand the principle, analysis, calculator, design of circuits. This course includes the theory teaching and the experiment teaching. Therefore the online teaching method for this course is studied for the theory teaching and the experiment teaching, respectively.

\section{Online Theory Teaching}

In the traditional teaching method, the teachers use the classroom teaching, the multimedia teaching, and the face to face discussion to realize the theory teaching. In the teaching process of high frequency circuit, the students are required to grasp the principle, calculation, and design of several typical circuits. In contrast to the face to face teaching, the online teaching is lack of immersion. Furthermore, the teacher does not know whether the students listen in class carefully where the online classroom has many students. In order to assure the online teaching quality of this course, we try to improve the teaching process.

In the online teaching operation, we prepare the e-documents, videos and PPTs in advance and send these teaching materials to the students before the online teaching so that the students study the course contents before class. Therefore we ask for the student to pre-study the teaching materials of the next lesson. In the online class, we use the discussion as the main method instead of the lecture. At first, the teachers know about the students' acquisition of knowledge better by discussion. Secondly, random question and discussion lets the students pre-study the course contents carefully. Thirdly, the student also stay focused in the online class because the student selection for discussion is random. In our online teaching process, the effect of this method is better than the traditional online teaching.

\section{Online Experiment Teaching}

The experimental teaching is an organization form of the practical teaching. The students use the instruments and the equipment to realize the experimental target under the artificially controlled conditions, and gain knowledge and development capabilities through observation, measurement, and analysis. It is widely used in basic courses and professional courses. However, it's difficult to operate the online experimental teaching because the students do not use the adequate instruments out of campus.

In order to decrease the epidemic influence on experimental teaching, we divide the experiments into two parts. One part of experiments is the students have to use the real instruments to complete the experiments. For this part, our method is to delay them until the campus reopens. The aim of another part is to understand the principle and design of circuits by circuit test. Our method is to use Multisim to simulate these circuits. Figure 1 shows the simulation of high frequency resonant amplifier using Multisim. 


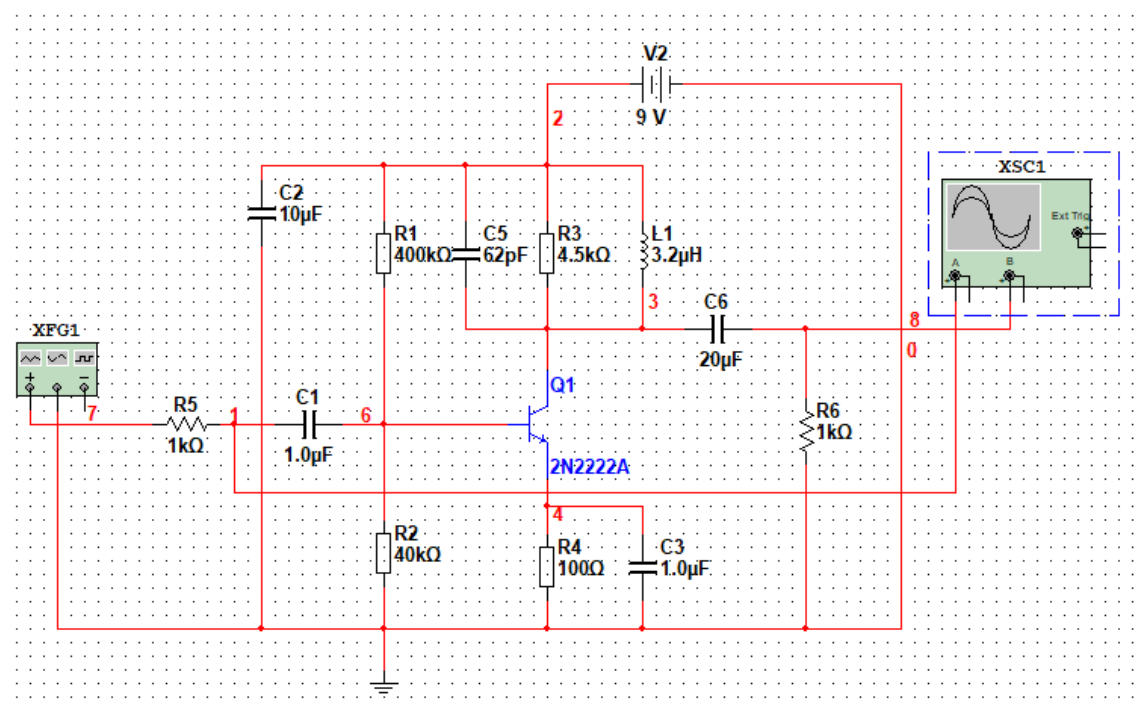

Figure 1. Simulation of high frequency resonant amplifier using Multisim.

\section{Analysis on Teaching Effect}

We compare the teaching effect (Board SRE, 2006) between the classroom teaching and our online teaching. The data of classroom teaching is gathered in 2018 and 2019, while the data of online teaching is obtained in the epidemic period. The accuracy of which the students answer the question is $68.2 \%$ in classroom teaching and $76.8 \%$ in online teaching. Since we require the students self-study the content of next lesson before online class, the accuracy in the online teaching is higher than the classroom teaching. In online teaching, the interactivity between teacher and students is better than the classroom teaching because the students think the online teaching is a novel teaching style. Most students are satisfied with the online teaching method. Moreover, most students accept the method which uses Multisim simulation to do the part of experiments.

\section{Conclusion}

The entire online teaching is implemented on university firstly because of COVID-19 epidemic. In our online teaching practice, we consider the feature of online teaching and propose the novel method for online teaching. This method is used in the online teaching of high frequency circuit. In the process of teaching, most students think this method has better interactivity between teacher and students. This online teaching method should be applied in other courses teaching in online university education.

\section{Acknowledgements}

The generous support of the Discipline Construction Fund of SSPU (XXKZD1605) and the Construction of University Enterprise Cooperation Automobile Electronic Joint Experiment Center (A11NH182016) are gratefully acknowledged. 


\section{Conflicts of Interest}

The authors declare no conflicts of interest regarding the publication of this paper.

\section{References}

SRE Board (2006). Standards for Quality Online Teaching. Southern Regional Education Board, 12.

Cuellar, N. (2002). The Transition from Classroom to Online Teaching. Nursing Forum, $37,5-13$.

Goodyear, P., Salmon, G., Spector, J. M., et al. (2001). Competences for Online Teaching: A Special Report. Educational Technology Research and Development, 49, 65-72.

Nelson, R. (2010). Discussion-Based Online Teaching to Enhance Student Learning: Theory, Practice and Assessment. Teaching theology \& religion, 9, 194-195. 